\title{
Association of Chest Radiograph with Community Acquired Pneumonia among the Children Admitted in Dhaka Shishu Hospital
}

Akhand Tanzih Sultana ${ }^{1}$, Mamun Miah² ${ }^{2}$ Kazi Zahidul Hoque ${ }^{3}$, Jostna Ara Begum4 ${ }^{4}$ Kamruzzaman ${ }^{5}$, Nazia ${ }^{6}$

\begin{abstract}
Background: Community-acquired pneumonia (CAP) is an infectious disease and common reason for hospitalization of children throughout the world. There are few published data about radiological findings and their relationship with community-acquired pneumonia (CAP) severity. Objective: This study was conducted to evaluate radiological findings in children with community acquired pneumonia (CAP) of different severity. Materials and method: A prospective study was conducted in the department of Paediatric Respiratory Medicine (Pulmonology) in Dhaka Shishu Hospital from November 2016 and April 2017. A total number of 35 children of 1 month to 10 years, who were admitted with cough or respiratory difficulty and radiological pneumonia were included in this study. Results: Majority of the study participants 18 (51.43\%) were infants with a male preponderance. The most common symptom was cough (94.29\%) followed by fever (82.86\%) and respiratory distress $(42.86 \%)$. Crepitation (54.29\%), tachypnoea (42.86\%) and chest indrawing (28.57\%) were the most common signs. Out of total 35 children 17 (48.57\%) cases had pneumonia and 18 (51.43\%) cases had severe pneumonia. Among chest X-rays, severe pneumonia had greatest frequency of primary end point consolidation (PEP) on right side $(n=10$, $55.55 \%)$, right infiltrates $(n=5,27.78 \%)$, bilateral infiltrates $(n=2,11.11 \%)$ followed by right sided pleural effusion $(n=3,16.67 \%)$ and pneumothorax $(n=2,11.11 \%)$. There was no association found between CAP severity and presence of radiological findings of pneumonia. Conclusion: This study shows that severe CAP may not always be associated with positive radiological findings. This finding may be taken into consideration during the diagnosis and management of CAP.
\end{abstract}

Keywords: Community-acquired pneumonia (CAP); tachypnea; primary end point consolidation (PEP); infiltrate.

Delta Med Col J. Jan 2019;7(1):21-25

1. Assistant Professor, Dept. of Pulmonology, Bangladesh Institute of Child Health (BICH), Dhaka Shishu (Children) Hospital, Dhaka, Bangladesh.

2. Assistant Professor, Dept. of Rheumatology, Bangladesh Institute of Child Health (BICH), Dhaka Shishu (Children) Hospital, Dhaka, Bangladesh.

3. Assistant Professor, Dept. of Paediatric Cardiac Surgery, Bangladesh Institute of Child Health (BICH), Dhaka Shishu (Children) Hospital, Dhaka, Bangladesh.

4. Associate Professor, Dept. of Pulmonology, Bangladesh Institute of Child Health (BICH), Dhaka Shishu (Children) Hospital, Dhaka, Bangladesh.

5. Registrar, Dept.of Pulmonology, Bangladesh Institute of Child Health (BICH), Dhaka Shishu (Children) Hospital, Dhaka, Bangladesh.

6. Resident Medical Officer, Dept. of Pulmonology, Bangladesh Institute of Child Health (BICH), Dhaka Shishu (Children) Hospital, Dhaka, Bangladesh.

Correspondence: Dr. Akhand Tanzih Sultana. e-mail: dratsultana@gmail.com 


\section{Introduction}

Community acquired pneumonia (CAP) is defined clinically as presence of signs and symptoms of pneumonia in a previously healthy child due to an infection which has been acquired outside hospital. ${ }^{1}$ Annually, approximately 120-156 million cases of acute lower respiratory infections (ALRI) occur globally, with approximately 1.4 million resulting in death. ${ }^{2-5}$ Of these, pneumonia kills an estimated 1 million children under the age of 5 every year and accounts for $15 \%$ of deaths in children $<5$ year of age, ${ }^{6}$ with $90-95 \%$ of these deaths occurring in the developing world. ${ }^{7}$

The majority of pneumonia episodes in children $<5$ year of age occurs in just 15 countries, with South Asia and Sub-Saharan Africa collectively enduring the largest burden of more than half the worldwide total cases of pneumonia in children. ${ }^{2,8}$ But early diagnosis and intervention can effectively reduce mortality. In order to make a definite diagnosis of clinical pneumonia one might need invasive procedure, which makes more difficulties in identifying the causative organisms. ${ }^{9}$ Therefore, chest X-ray can give useful information about the presence of pneumonia. ${ }^{10}$ But appropriateness of performing chest radiography in children with CAP is still on debate and the actual guidelines recommend for verification of complications in patients with severe CAP. ${ }^{11,12}$

Therefore, the present study was designed to evaluate radiological findings in children with community acquired pneumonia (CAP) of different severity.

\section{Materials and method}

A prospective clinical study was conducted in the department of Paediatric Respiratory Medicine (Pulmonology) in Dhaka Shishu Hospital, Dhaka, Bangladesh, over a period of 6 months (November 2016 and April 2017). A total number of 35 children of both sexes in the age group of 1 month to 10 years, admitted with community acquired pneumonia (CAP) were included in this study. They presented with cough and respiratory distress and radiological pneumonia. Children with congenital anomalies of heart and lungs, anatomical defects like cleft lip and palate, immune deficiency, known case of asthma were excluded. Written informed consent was obtained from all guardians of the patients. A detailed history of the relevant symptoms such as fever, cough, rapid breathing, wheezing, etc. was taken. A detailed general examination of each child including anthropometry was carried out. Detailed systematic examination was done. Any associated illness such as diarrhoea, congestive cardiac failure if present was noted. Socio economic history, immunization status were also recorded and all the data were collected in structured questionnaire. Investigations included chest $\mathrm{X}$-ray, $\mathrm{CBC}$ and blood culture. Pneumonia was defined radiologically as the presence of end-point consolidation or other (non-end-point) infiltrate in lungs according to the WHO radiological classification of pneumonia ${ }^{13}$ and the finding was confirmed independently by a radiologist and a paediatrician. Categorical variables are given as numbers and percentages and were analyzed using cross table analysis with the Pearson chi-square test. All data were entered into SPSS for Windows (version 21.0; SPSS Inc, Chicago, IL).

\section{Results}

Among the total of 35 paediatric patients diagnosed with community acquired pneumonia (CAP) majority (51.43\%) were infants. There was a male preponderance. Male were $65.71 \%$ and female were $34.29 \%$ (Table I). 
Table I: Gender and age distribution of children in the study $(\mathrm{N}=35)$

\begin{tabular}{lcc}
\hline Characteristic & Number of children & Percentage \\
\hline Gender & 23 & 65.71 \\
$\quad$ Male & 12 & 34.29 \\
Female & & \\
Age (in years) & 18 & 51.43 \\
$<1$ & 07 & 20.00 \\
$1-2$ & 03 & 08.57 \\
$3-5$ & 07 & 20.00 \\
$>5$ & & \\
\hline
\end{tabular}

The most common symptom was cough in 33 patients $(94.29 \%)$ followed by fever in 29 patients $(82.86 \%)$ and respiratory distress in 15 patients (42.86\%) (Table II).

Table II: Presenting symptoms of children in the study $(\mathrm{N}=35)$

\begin{tabular}{lcc}
\hline Symptoms & Number of cases & Percentage \\
\hline Cough & 33 & 94.29 \\
Fever & 29 & 82.86 \\
Respiratory distress & 15 & 42.86 \\
Chest pain & 01 & 02.86 \\
Abdominal pain & 01 & 02.86
\end{tabular}

Crepitation (54.29\%), tachypnoea (42.86\%) and chest indrawing $(28.57 \%)$ were the most common signs. (Fig 1)

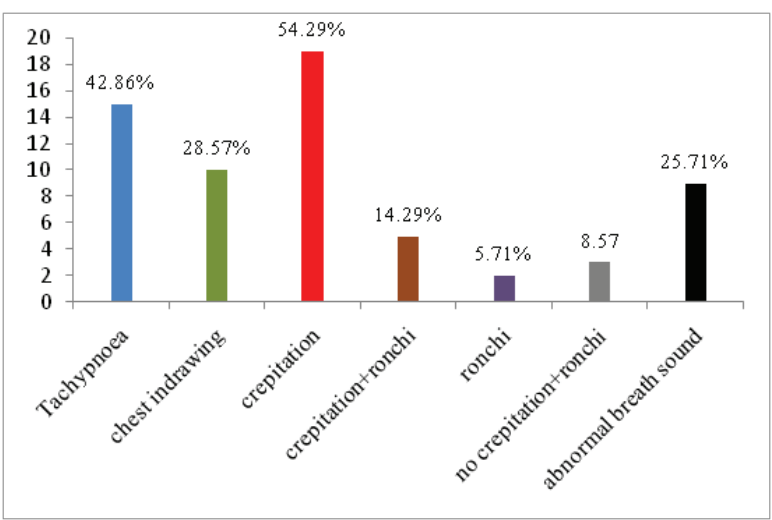

Fig 1: Clinical presentation in the studied children

Out of total 35 children $17(48.57 \%)$ cases had community acquired pneumonia and 18 (51.43\%) cases had severe community acquired pneumonia. Chest X-rays revealed that severe pneumonia had greatest frequency of primary end point consolidation on right side $(\mathrm{n}=10,55.55 \%)$, right infiltrates $(n=5,27.78 \%)$, bilateral infiltrates $(n=2$, $11.11 \%$ ) followed by right sided pleural effusion $(\mathrm{n}=3, \quad 16.67 \%)$ and pneumothorax $(\mathrm{n}=2$, $11.11 \%)$.There was no significant radiological association with severity of pneumonia. (Table III)

Table III: Radiological association with severity of pneumonia

\begin{tabular}{lccc}
\hline Chest X-ray findings & $\begin{array}{c}\text { Pneumonia } \\
\text { Frequency (\%) }\end{array}$ & $\begin{array}{c}\text { Severe Pneumonia } \\
\text { Frequency (\%) }\end{array}$ & p value \\
\hline $\begin{array}{l}\text { Primary end point consolidation } \\
\text { Right }\end{array}$ & $03(17.65)$ & $10(55.55)$ & \\
Left & $03(17.65)$ & $02(11.11)$ & 0.131 \\
Bilateral & $03(17.65)$ & $01(5.55)$ & \\
Other infiltrates & & & \\
Right & $09(52.94)$ & $05(27.78)$ & \\
Left & 0 & 0 & 0.274 \\
Bilateral & $02(11.76)$ & $02(11.11)$ & \\
Pleural effusion & & & 0.222 \\
Right & $01(5.88)$ & & \\
Left & $02(11.76)$ & & 0.257 \\
Pneumothorax & & 0 & \\
Right & 0 & 0 & \\
Left & 0 & & \\
\hline
\end{tabular}

\section{Discussion}

In our study a total of 35 paediatric patients diagnosed with community acquired pneumonia (CAP) were included. Male predominance was seen. Male were $65.71 \%$ and female were $34.29 \%$. A study conducted by Arpitha et al. showed a male preponderance with a sex ratio of 1.05:1.14 The most common age group affected was <1year which was similar to results found in other studies. ${ }^{15-17}$ Cough was the predominant symptom found in $94.29 \%$ of patients, followed by fever $(82.86 \%)$, respiratory distress $(42.86 \%)$ and others. The incidence of presenting symptoms in our study is comparable with studies conducted by Kabra et al. and Kumar et al. ${ }^{18,19}$ In our study crepitation $(54.29 \%)$, tachypnea $(42.86 \%)$ and chest indrawing (28.57\%) were the most common signs. Some other studies observed that tachypnoea and chest retractions were highly specific signs in detecting pneumonia. ${ }^{20,21}$ Reddaiah et al. reported that crepitation were found in $76 \%$ and rhonchi 
in $23.2 \%$ of patients of pneumonia which was similar to our study. ${ }^{22}$

The radiographic appearance of pneumonia varies with age and with pathogenesis and extent of the disease. ${ }^{23}$ The present study showed that out of total 35 children $17(48.57 \%)$ cases had community acquired pneumonia (CAP) and 18 $(51.43 \%)$ cases had severe community acquired pneumonia (severe CAP) and showed a significant association of primary end point consolidation (55.55\%), other infiltrates $(27.78 \%)$ and bilateral infiltrates $(11.11 \%)$ with severe pneumonia. Primary end point consolidations were more prevalent in the right than the left lung. Pleural effusion $(n=3,16.67 \%)$ and pneumothorax $(n=2$, $11.11 \%$ ) was also more in right side. However, our findings are more or less similar to the Spanish and Sudanian studies where chest X-ray proved pneumonia in $62.1 \%$ of cases. 9,24 But a recent Indian study showed a significant association of bilateral infiltrates with severe pneumonia than Primary end point consolidation and other infiltrates. ${ }^{25}$ Patria et al. showed that parenchymal infiltrates and consolidation were more prevalent in the right than the left lung. ${ }^{26}$

We did not find any association between CAP severity and presences of radiological findings of pneumonia. No data are available on the association between severe bacterial CAP and radiographic findings. However, Patria et al. found a significant association between severity and right hilar involvement in her study. ${ }^{26}$

The limitations of our study include the lack of etiological data and other laboratory biomarkers. The number of sample size was small in relation to huge number of population. Long term outcome of the patients were not also assessed.

This study shows that severe CAP may not always be associated with positive radiological findings. This finding may be taken into consideration during the diagnosis and management of CAP and chest X-ray is not recommended for routine use in the diagnosis and management of CAP.

\section{References}

1. Harris M, Clark J, Coote N, Fletcher P, Harnden A, McKean M, et al. British Thoracic Society Guidelines for the Management of Community Acquired Pneumonia in Children: Update 2011. Thorax. 2011;66(Supp12):Sii1-ii23.

2. Walker CL, Rudan I, Liu L, Nair H, Theodoratou E, Bhutta ZA, et al. Global Burden of Childhood Pneumonia and Diarrhoea. Lancet. 2013;381:1405-16.

3. Rudan I, O'Brien KL, Nair H, Liu L, Theodoratou E, Qazi S, et al. Epidemiology and Etiology of Childhood Pneumonia in 2010: Estimates of Incidence, Severe Morbidity, Mortality, Underlying Risk Factors and Causative Pathogens for 192 Countries. J Glob Health. 2013;3:010401.

4. Liu L, Johnson HL, Cousens S, Perin J, Scott S, Lawn JE, et al. Global, Regional, and National Causes of Child Mortality: an Updated Systematic Analysis for 2010 with Time Trends since 2000. Lancet. 2012;379:2151-61.

5. Sonego M, Pellegrin MC, Becker G, Lazzerini M. Risk Factors for Mortality from Acute Lower Respiratory Infections (ALRI) in Children Under Five Years of Age in Low and Middle-Income Countries: a Systematic Review and Meta-Analysis of Observational Studies. PLoS One. 2015; 10:e0116380.

6. www.who.int [Internet]. WHO Fact sheet N331 [Updated 2015 Nov cited 2017 July 15]. Available at: ht t p : / / w w w. who.int/mediacentre/ factsheets/fs331/en/.

7. Zar HJ, Ferkol TW. The Global Burden of Respiratory Disease-Impact on Child Health. Pediatr Pulmonol. 2014;49:430-34.

8. Rudan I, Boschi-Pinto C, Biloglav Z, Mulholland K, Campbell H. Epidemiology and Etiology of Childhood Pneumonia. Bull World Health Organ. 2008;86:408-16.

9. Ali Salih KEM, Wahb OA, Ibrahim SA. Radiological Findings in Severe Pneumonia in Children 1-59 Months in a Children's Hospital, Khartoum, Sudan. Pediatr Therapeut. 2012;2(3):1000117.

10. Vuori-Holopainen E, Peltola H. Reappraisal of Lung Tap: Review of an Old Method for Better Etiologic Diagnosis of Childhood Pneumonia. Clin Infect Dis. 2001;32:715-26.

11. Bradley JS, Byington CL, Shah SS, Alverson B, Carter ER, Harrison C, et al. Executive Summary: The Management of Community-Acquired 
Pneumonia in Infants and Children Older Than 3 Months of Age: Clinical Practice Guidelines by the Pediatric Infectious Diseases Society and the Infectious Diseases Society of America. Clin Infect Dis. 2011;53:617-30.

12. Esposito S, Cohen R, Domingo JD, Pecurariu OF, Greenberg D, Heininger U, et al. Antibiotic Therapy for Pediatric Community-Acquired Pneumonia: Do We Know When, What and for How Long to Treat? Pediatr Infect Dis J. 2012;31:78-85.

13. Cherian T, Mulholland EK, Carlin JB, Ostensen H, Amin R, de Campo M, et al. Standardized Interpretation of Paediatric Chest Radiographs for the Diagnosis of Pneumonia in Epidemiological Studies. Bull World Health Organ. 2005;83:353-59.

14. Arpitha G, Rehman MA, Ashwitha G. Effect of Severity of Malnutrition on Pneumonia in Childern Aged 2M-5Y at a Tertiary Care Center in Khammam, Andhra Pradesh: A Clinical Study. Scholars J Applied Medical Sciences. 2014; 2(6E):3199-203.

15. Basnet S, Sharma A, Mathisen M, Shrestha PS, Ghimire RK, Shrestha DM, et al. Predictors of Duration and Treatment Failure of Severe Pneumonia in Hospitalized Young Nepalese Children. PLoS One. 2015;10(3):0122052.

16. Mathisen M, Strand TA, Sharma BN, Chandyo RK, Valentiner-Branth $\mathrm{P}$, Basnet $\mathrm{S}$, et al. Clinical Presentation and Severity of Viral Community-Acquired Pneumonia in Young Nepalese Children. Pediatr Infect Dis J. 2010;29(1):1-6.

17. Kuti BP, Adegoke SA, Oyelami OA. Can We Predict Which Children with Clinical Pneumonia Will Have Radiologic Findings On Chest Radiograph? World Journal of Medicine and Medical Science: 2014;2(3):1-12.
18. Kabra SK, Broor S, Lodha R, Maitreyi RS, Ghosh M, Pandey RM, et al. Can we Identify Acute Severe Viral Lower Respiratory Tract Infection Clinically? Indian Pediatr. 2004;41:245-49.

19. Kumar N, Singh N, Locham KK, Garg R, Sarwal D. Clinical Evaluation of Acute Respiratory Distress and Chest Wheezing in Infants. Indian Pediatr. 2002;39:478-83.

20. Prabakar S, Ramanathan R, Lakshmi Sarayu Y. Clinical Profile and Outcome of Pneumonia in Children. JMSCR. 2016;4(10):13284-89.

21. Palafox M, Guiscafre H, Reyes H, Mufioz O, Martinez H. Diagnostic Value of Tachypnoea in Pneumonia Defined Radiologically. Arch Dis Child. 2000;82:41-45.

22. Reddaiah VP, Kapoor SK. Acute Respiratory Infections in under Five: Experience at Comprehensive Rural Health Services Project Hospital Ballabgarh. Indian J Community Med. 1995;20(2):13-18.

23. Kuhn JP, SlovisTL, Haller JO. Caffey's Pediatric Diagnostic Imaging. 10th ed, vol 1. Missouri: Mosby; 2003. p.987-95.

24. Gustavo C, Eider O, Edurado GP, Agustin N, Emilio PT. Incidence of Hospitalization Due to Pneumonia in Children Aged Less Than 5 Years. Open Infect Dis J. 2009;3:27-30.

25. Jain DL, Mishra S, Jain H, Reddy M, Agrawal SB. Role of Chest X-Ray in Assessing Severity of Pneumonia in Children Aged 3 Months to 59 Months. J Pediatr Res. 2017;4(03):242-48.

26. Patria MF, Longhi B, Lelii M, Galeone C, Pavesi MA, Esposito S. Association between Radiological Findings and Severity of Community-Acquired Pneumonia in Children. Ital J Pediatr. 2013;39:56. 